Cui, Zhan-Feng; Hu, D. - C.

\title{
Flow and Riverbed Erosion-Deposition Simulation around Submerged Water Intake
}

Zur Verfügung gestellt in Kooperation mit / Provided in Cooperation with:

Kuratorium für Forschung im Küsteningenieurwesen (KFKI)

Verfügbar unter / Available at:

https://hdl.handle.net/20.500.11970/99472

Vorgeschlagene Zitierweise / Suggested citation:

Cui, Zhan-Feng; Hu, D. - C. (2014): Flow and Riverbed Erosion-Deposition Simulation around Submerged Water Intake. In: Lehfeldt, Rainer; Kopmann, Rebekka (Hg.): ICHE 2014. Proceedings of the 11th International Conference on Hydroscience \& Engineering, September 28 - October 2, 2014, Hamburg, Germany. Karlsruhe: Bundesanstalt für Wasserbau. S. 531-538. 


\title{
Flow and Riverbed Erosion-Deposition Simulation around Submerged Water Intake
}

\author{
Z.-F. Cui \& D.-C. Hu \\ Yangtze River Scientific Research Institute, Wuhan, China
}

\begin{abstract}
The research on flow movement and the riverbed erosion-deposition around the water intake is essential for the safe operation of water intake engineering. And it is necessary to demonstrate the reasonableness of the position of the water intake from the terms of flow pattern, the river regime and reduce the impact of water intaking on the fairways and flood control etc.. As an example, water intakes of one power plant locate at downstream of Yangtze River were selected in this paper. And a 3D numerical model is used to simulate local flows (as shown in Fig.1) and plane 2D flow and sediment model is used to simulate riverbed erosion-deposition, suspended sediment concentration around submerged water intakes, respectively. And recent riverbed evolutions around the water intakes were predicted and so on. The boundary conditions of 3D flow model provided by the calculation results of 2D model. The watersediment condition of typical series and high flow year, moderate flow year and low flow year typical year were selected. And the reservoir operation impact of the Three Gorges Project and the upstream reservoir to the water-sediment process downstream were take into account. Then, the better location and appropriate elevation of water intake were recommended based on the calculations result of models through analyzing the change of riverbed erosion-deposition, bed elevation and suspended sediment concentration around water intakes (as shown in Fig.2). The results show that the change of riverbed erosion and deposition around the water intake is not only affected by the conditions of incoming water and sediment, but also by the position of the local topography at the same river reach. Therefore, it is essential to select the appropriate location and elevation to the water intake engineering.
\end{abstract}

Keywords: Water intake engineering, Riverbed erosion-deposition, 3D numerical model, 2D numerical model

\section{INTRODUCTION}

With the rapid development of China's industrialization and urbanization, the demand for electricity is growing, and the number of thermal power projects is increasing. In order to ensure the normal supply cooling water of thermal power plant, planning layout for cooling water intakes is necessary. Then, the primary problem is analysis riverbed erosion-deposition and characteristics of sediment movement at the intakes (CHEN $(2008)^{[1]}$, DUAN $(1997)^{[2]}$, ZHANG $\left.(2006)^{[3]}\right)$. So, it is essential to the safe operation of power plants in the future.

The water intake from river have two kinds: the open channel type and submerged type mainly (ZHOU $\left.(1997)^{[4]}\right)$. The former use open channel to carry water in tortuous channel. And the latter use pipeline to carry water (ZHAO (2003)) $)^{[5]}$. Since 1958, China began independent research the thermal power generation, with the rapid development of thermal power generation, the study of sediment problems in river water intake station also get some achievements. XIE $(2005)^{[6]}$, and ZHANG (2013) ${ }^{[7]}$ adopted numerical simulation to research the characteristics of flow and sediment movement. HU (2013) ${ }^{[8]}$ use 3D numerical model to simulate flows around submerged water intakes. The layout of water intakes are effected by many factors, such as the river regime of intake section located, the changes of bed elevation, flow and sediment concentration, structures of water intake at the head of water intakes. These factors are likely to affect the safe operation of water intakes, which lack of consideration in most models. 
In this paper, a 3D numerical model is used to simulate local flows. And the plane 2D flow and sediment model is used to simulate riverbed erosion-deposition, suspended sediment concentration around submerged water intakes. At the same time, the $2 \mathrm{D}$ model is used to research the effect of river regime change, bed elevation change, sediment concentration and other factors to water intakes projects.

\section{MODELING}

\section{$2.13 D$ modeling}

A semi-implicit 3D numerical model for non-hydrostatic pressure on an unstructured $\sigma$ grid was adopted. In the model, governing equations use the 3D Reynolds time-averaged equations (NS equations) based on assumption of Boussinesq isotropic turbulence. And the turbulent stresses are calculated with $\varepsilon-\mathrm{k}$ model.

The pressure decomposition technique and $\theta$ semi-implicit method are used, with the solution procedure being split into two steps. First, with the implicit parts of non-hydrostatic pressures excluded, the provisional velocity field and free surface are obtained by solving a 2-D Poisson equation. Second, the theory of the differential operator is employed to derive the 3-D Poisson equation for non-hydrostatic pressures, which is solved to obtain the non-hydrostatic pressures and to update the provisional velocity field. When the non-orthogonal sigma-coordinate transformation is introduced, additional terms come into being, resulting in a 15-diagonal, diagonally dominant but unsymmetric linear system in the 3-D Poisson equation for non-hydrostatic pressures. The Biconjugate Gradient Stabilized (BiCGstab) method is used to solve the resulting 3-D unsymmetric linear system instead of the conjugate gradient method, which can only be used for symmetric, positive-definite linear systems.

The detail of model equations and discretization can be found in the paper of $\mathrm{HU}\left(2011^{[9]}, 2013^{[10]}\right)$.

\subsection{2 flow and sediment modeling}

The governing equations of 2D include the flow continuity equation, suspended sediment diffusion equation, bedload unbalanced transport equation and riverbed deformation equation based on general curvilinear coordinates. Limited to the length, the equations are not list here.

FVM (finite volume method) and staggered grids were adopted in the 2D modeling. In computation, SIMPLE (Semi-Implicit Method for Pressure- Linked Equations) was adopted. Method of ADI and TDMA were linked to solve the discretized algebraic equations. And stop the computation when max residual error of every variable all little than $10^{-5}$.

\section{CALCULATION SCHEME AND RESULT}

Limited to the length, the results of calibration and verification for the $3 \mathrm{D}$ an $2 \mathrm{~d}$ modeling are not list in the paper.

\subsection{Water intake project profile}

A power plant located at the right bank of Hukou waterways, about $37 \mathrm{~km}$ downstream of Jiujiang Bridge in the Changjiang River, as shown in Fig.1. The power plant which include two 1000MW coal-fired units need intake water from Changjiang River. And the designed intake flow is about $1.0 \mathrm{~m}^{3} / \mathrm{s}$. Preliminary design provides four water intake location (intake 1 to 4 from upstream), so we need to filter out optimum location using the flow and sediment mathematical model.

In this water intake project, two structural styles, i.e. mushroom-style (intake 1 to 3 ) and single-sided box-style (intake 4) were considered. The bed elevation of first style is $-7.42 \mathrm{~m}$, and the diameter of mushroom is $3.5 \mathrm{~m}$. The bed elevation of second style is $3.46 \mathrm{~m}$, and the size of single-sided box is $4 \mathrm{~m} \times 2.5 \mathrm{~m}$ (high $\times$ wide).

\subsection{Calculation reach and grid partition}

The calculation reach of 2D model is about $66 \mathrm{~km}$, and the number of grid is $28800(360 \times 80)$ as shown in Fig.1. The calculation river reach of 3D model is about $13 \mathrm{~km}$, and the number of grid and node is 17209 and 16956 respectively (Fig.2). And river terrain data of Dec., 2011 was adopted as initial terrain data. 


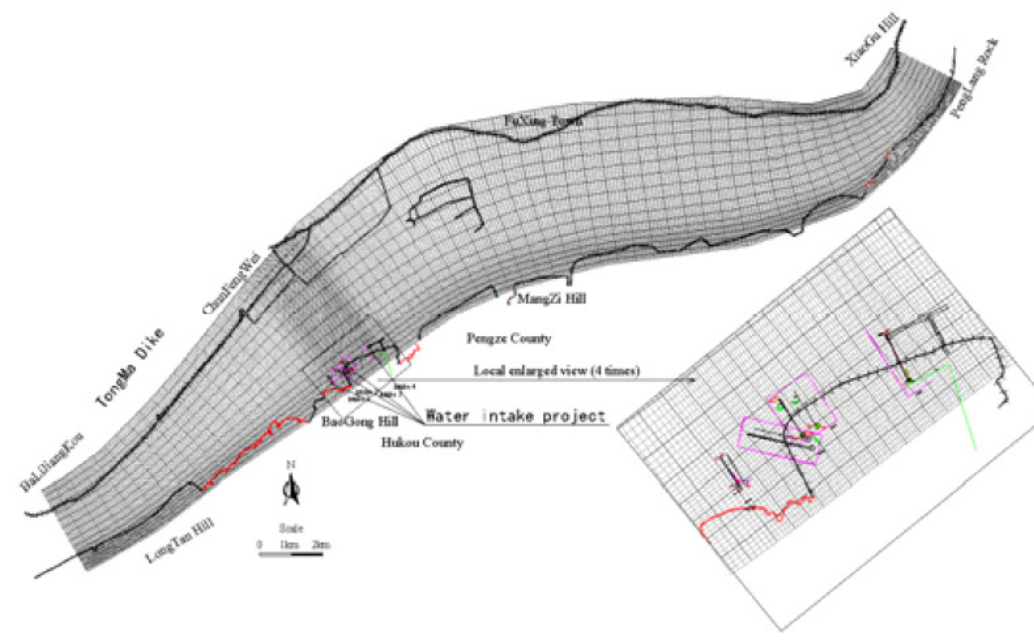

Figure 1. River regime and grid division of 2D.

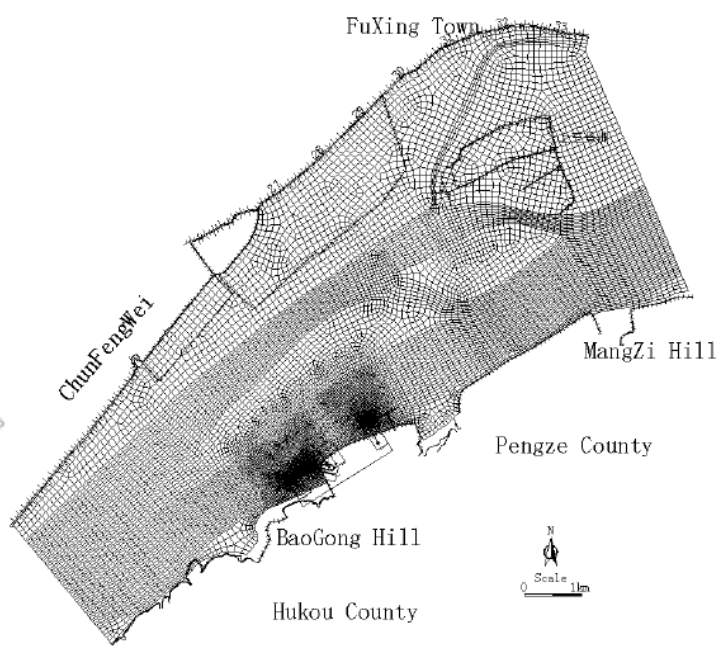

Figure 2. Plane view of grid division of 3D.

\subsection{Flow structure around water intake}

Table 1 give the computational flow conditions which are provided by 2D flow model. Fig.3 and Fig.4 give the velocity variation around the intake of style 1 and 2. Fig.5 give variation of vertical distribution of horizontal flow velocity around the intakes.

Table 1. Computational flow conditions and depths above the intake window (i.e. H in the tab below).

\begin{tabular}{|l|r|r|r|r|}
\hline \multirow{2}{*}{ case } & \multirow{2}{*}{ discharge } & \multirow{2}{*}{ outlet level } & \multicolumn{3}{l|}{$\mathrm{H}$} \\
\cline { 4 - 5 } & & & first style & second style \\
\hline Q1 & 83500 & 20.11 & 21.11 & 18.21 \\
\hline Q2 & 46000 & 16.09 & 16.92 & 14.14 \\
\hline Q3 & 28400 & 12.57 & 13.33 & 10.54 \\
\hline Q4 & 5360 & 3.99 & 4.48 & 1.79 \\
\hline
\end{tabular}

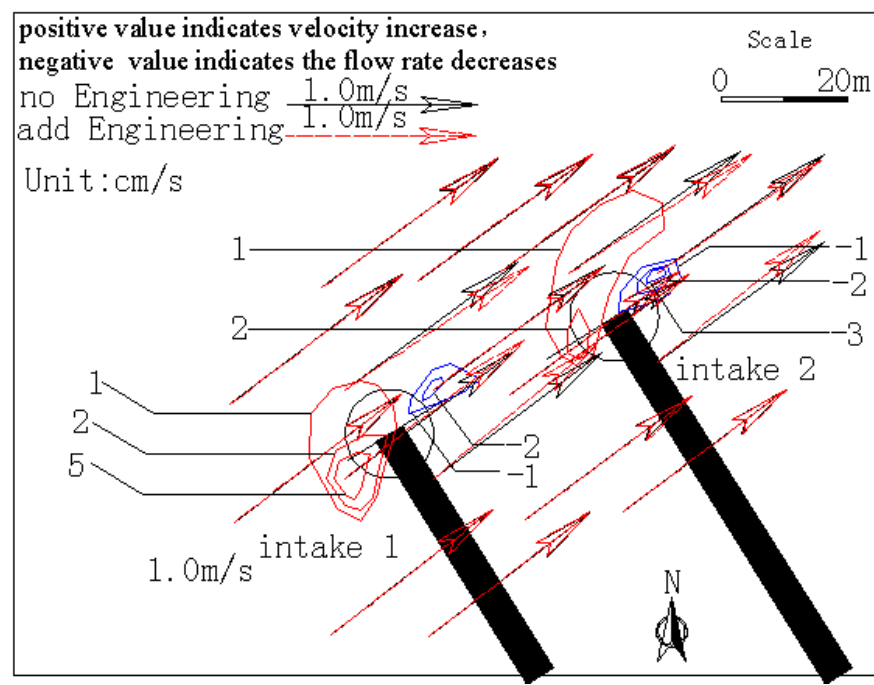

(a) layer of intake

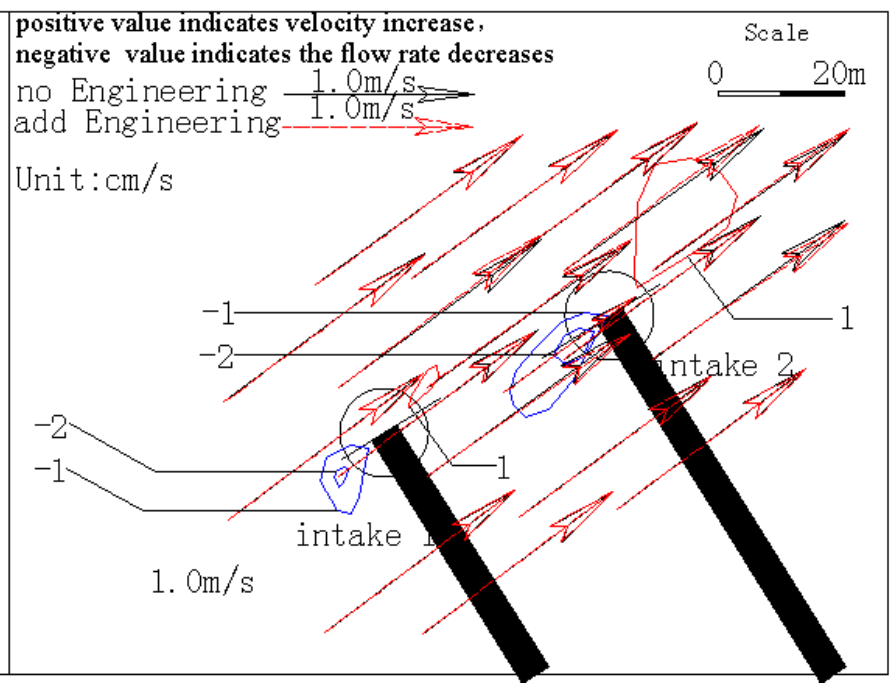

(b) layer of surface

Figure 3. Velocity variation around the intake of design 1. 


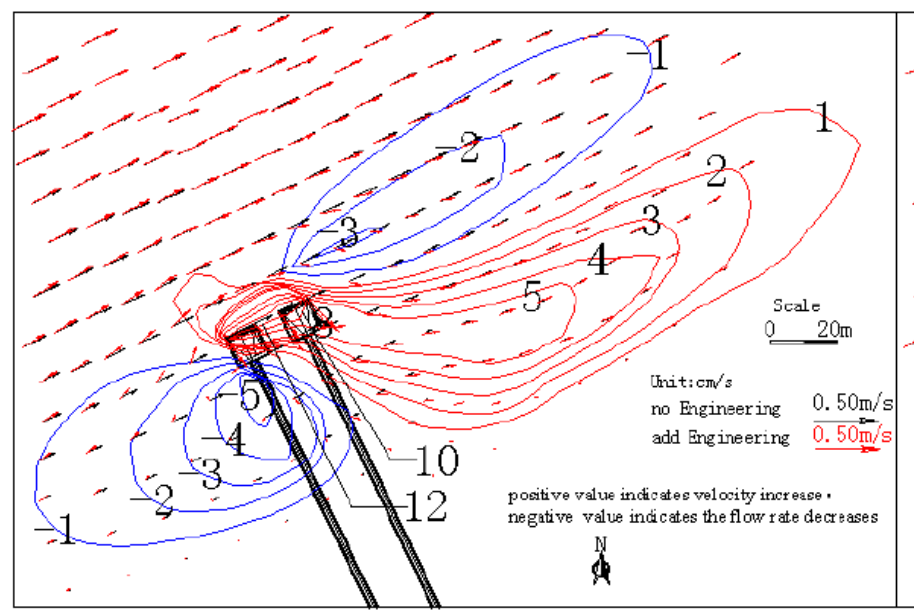

(a) layer of intake

Figure 4. Velocity variation around the intake of design 2.

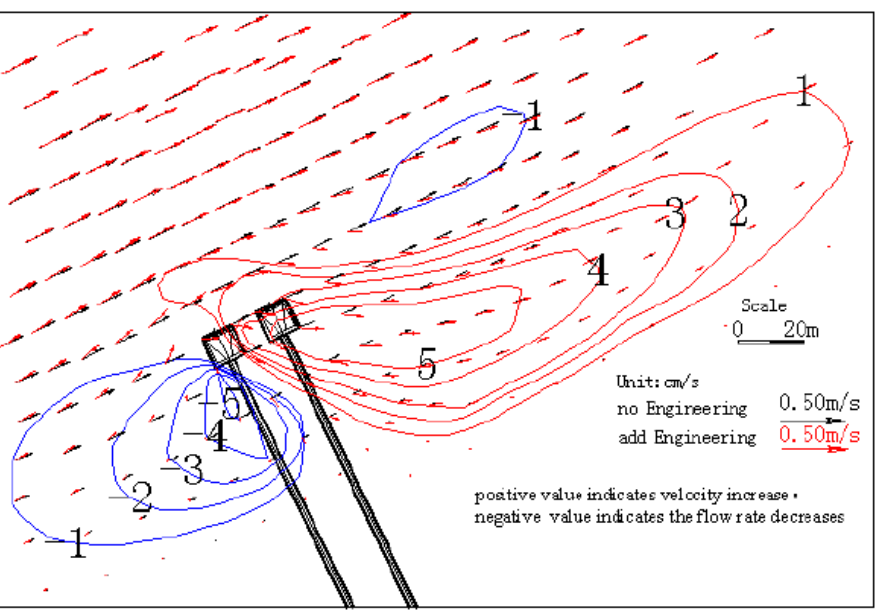

(b) layer of surface
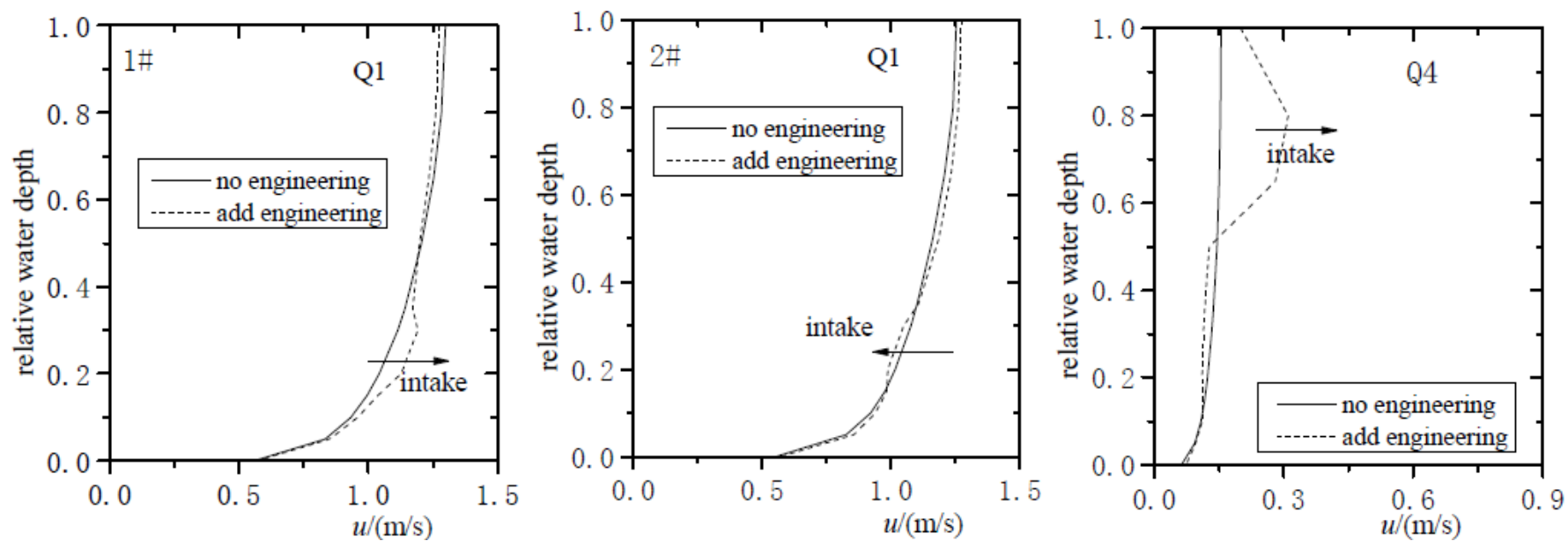

Figure 5. The change of velocity distribution around the intakes.

The results from Fig. 3 to Fig.5 show that the influence of water intake engineering to river flow is limited to local, and the flow velocity and direction change more under the condition of small flow discharge generally. And the zone of velocity increase and decrease appear alternately at upstream and downstream of two mushrooms for the style 1 . The velocity increase zone appear at downstream of the vertical of the leading edge line of intake box. And velocity decrease zone appear symmetrically on both sides of the velocity increase zone. These similarities and differences of two intake styles are caused by the difference between the mushroom style intake water from four sides and single-side style intake water from one side.

\subsection{Erosion-deposition simulation around the water intake}

\subsubsection{Calculation condition}

The flow and sediment conditions included typical years and typical series of years were adopted in modeling as shown in Tab.2. To the typical years, the flow and sediment of DaTong hydrometric station (which is located at 120km downstream of intake) of year 1998, 2010 and 2011 were select as the wet year, moderate flow year and dry year respectively. To the typical series, hydrological years from 2008$2011+1998$ (five years total) were selected. 
Table 2. Calculation conditions.

\begin{tabular}{|c|c|c|c|c|c|}
\hline Year & 2008 & 2009 & 2010 & 2011 & type 1998 \\
\hline runoff volume $\left(10^{8} \mathrm{~m}^{3}\right)$ & 8291 & 7826 & 10251 & 6671 & 12439 \\
\hline sediment discharge $\left(10^{11} \mathrm{~kg}\right)$ & 1.3 & 1.13 & 1.82 & 0.72 & 2.97 \\
\hline average sediment & 0.157 & 0.145 & 0.178 & 0.108 & 0.24 \\
\hline concentration $\left(\mathrm{kg} / \mathrm{m}^{3}\right)$ & & & & & \\
\hline remarks & $\begin{array}{c}\text { series } \\
\text { year }\end{array}$ & $\begin{array}{c}\text { series } \\
\text { year }\end{array}$ & $\begin{array}{c}\text { series year/ } \\
\text { moderate year }\end{array}$ & $\begin{array}{c}\text { series year/ } \\
\text { dry year }\end{array}$ & $\begin{array}{c}\text { series year/ } \\
\text { wet year }\end{array}$ \\
\hline
\end{tabular}

\subsubsection{Result and analyses}

Fig. 6 give the erosion-deposition distribution in different conditions.

From the calculation results, the change of erosion and deposition show the law of channel erosion and beach deposition. Also, amount of riverbed erosion-deposition has a close relationship with the incoming sediment. The amount of riverbed erosion is big when incoming sediment is little, vice-versa. Besides, riverbed erosion zone is located in the zone of inlet, outlet and mainstream near the intake. And the riverbed of near the right bank and left bottomland deposit about less than $3 \mathrm{~m}$.
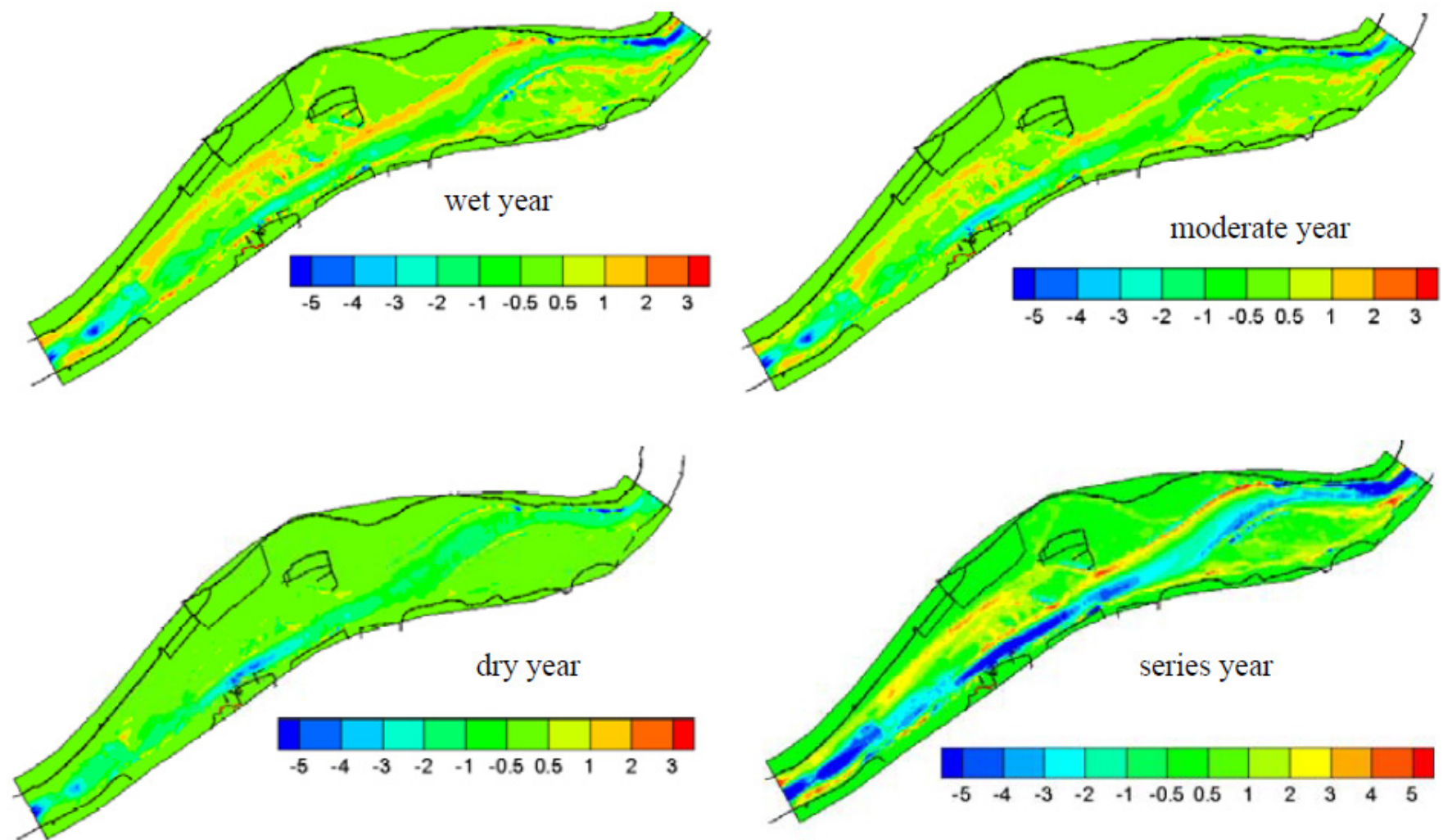

Figure 6. The erosion-deposition distribution in different conditions.

Fig. 7 shows the vary of bed elevation of four intake sections Fig. 8 shows the erosion-deposition variation process of four intakes. 

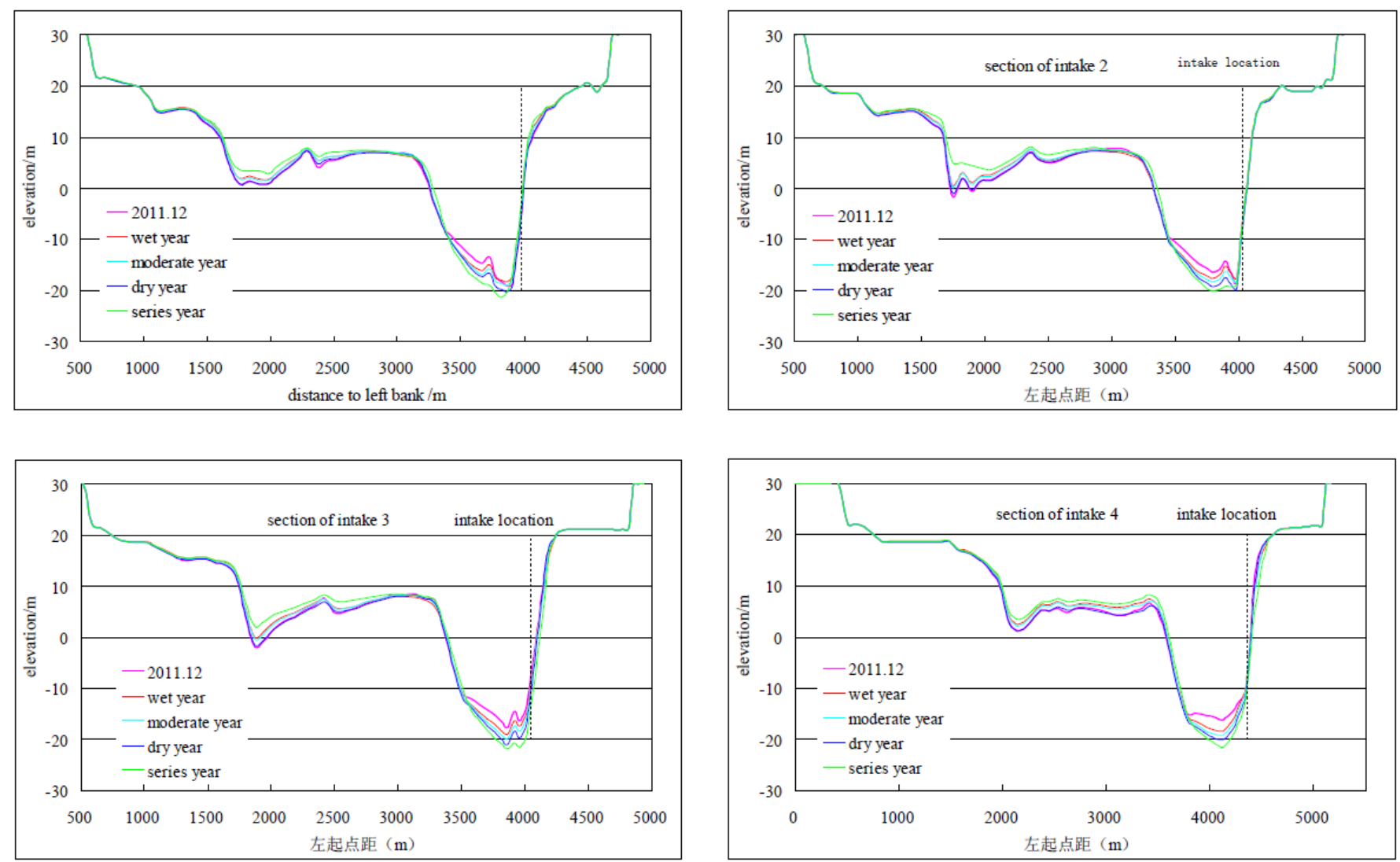

Figure 7. Variation of bed elevation of four intake sections.
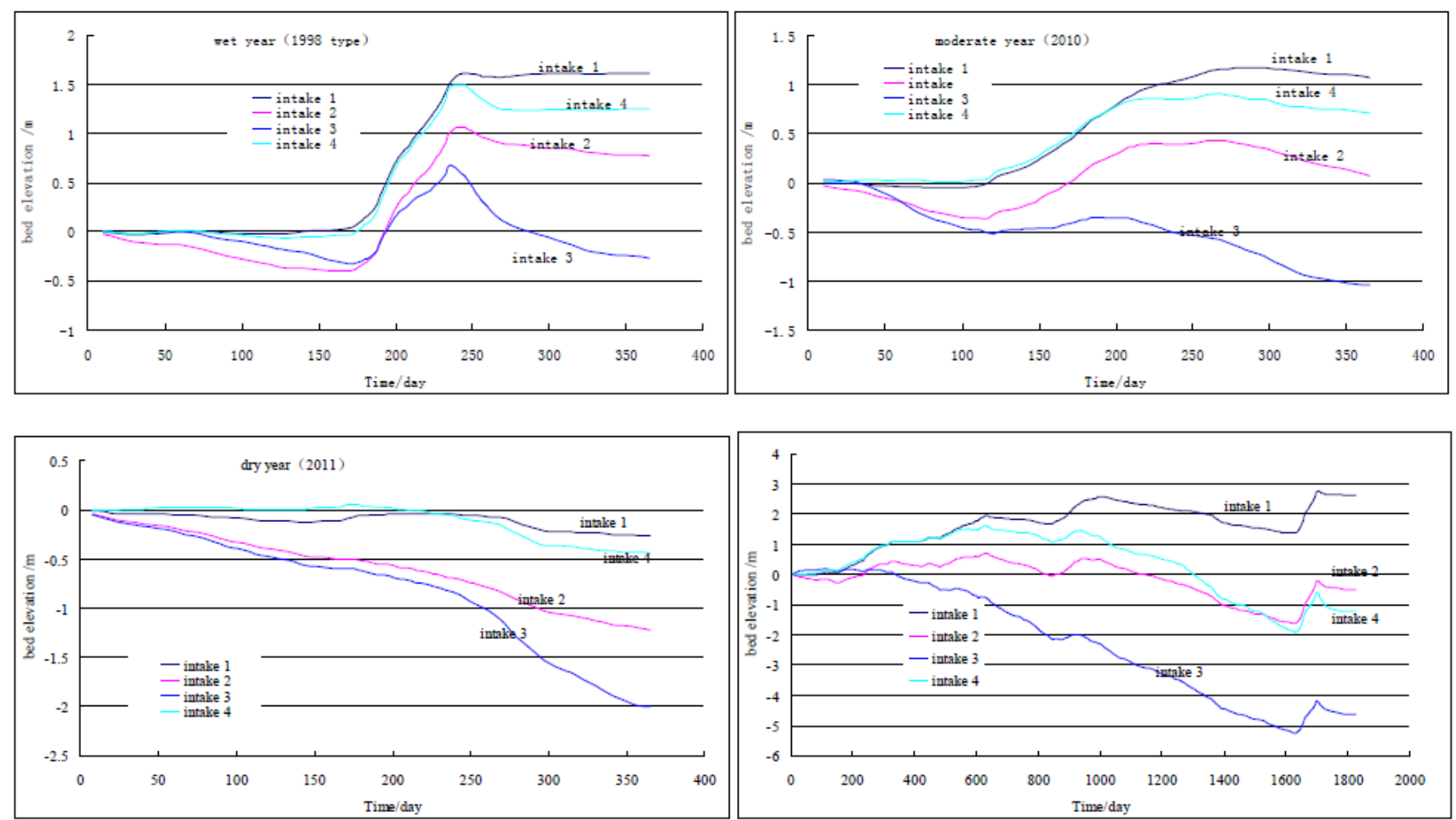

Figure 8. Variation process of bed elevation of four intakes gate.

After the completion of the Three Gorges Project, conditions for incoming water and sediment of the Yangtze river channel downstream from the Three Gorges reservoir will change, the sediment transport capacity of the river channel will be in an unsaturated state. So each section riverbed is scouring mainly. From Fig.7 and Fig.8, we know that the riverbed follows the law of sediment deposition on high-water period and sediment erosion on low-water period. 


\section{(1) Section of intake 1}

The section is scoured in the condition of dry year and both erosion and deposition in other conditions. There is slight deposit about 0.5-2.0m thickness at left bank beach and deposit about 1.0-2.0m thickness at right bank beach generally. The bed of the main channel is scoured about $1-3 \mathrm{~m}$. And the maximum thickness of bed erosion and deposition of the section is $3.9 \mathrm{~m}$ and $3.0 \mathrm{~m}$, respectively. On the other hand, the maximum thickness of bed erosion and deposition at intake gate is $0.3 \mathrm{~m}$ and $2.8 \mathrm{~m}$, respectively.

(2) Section of intake 2

The section is both erosion and deposition in all conditions. There is slight deposit about 0.5-3.0m thickness at left bank beach and deposit less than 1.0m thickness at right bank beach generally. The bed of the main channel is scoured about $1-3 \mathrm{~m}$. And the maximum thickness of bed erosion and deposition is $4.9 \mathrm{~m}$ and $5.0 \mathrm{~m}$, respectively.On the other hand ,the maximum thickness of bed erosion and deposition at intake gate is $1.6 \mathrm{~m}$ and $1.1 \mathrm{~m}$, respectively.

(3) Section of intake 3

The section is both erosion and deposition in all conditions. There is slight deposit about $0.5-3.0 \mathrm{~m}$ thickness at left bank beach generally. The bed of the main channel is scoured about $1-4 \mathrm{~m}$. And the maximum thickness of bed erosion and deposition is $8.5 \mathrm{~m}$ and $4.0 \mathrm{~m}$, respectively.On the other hand, the maximum thickness of bed erosion and deposition at intake gate is $5.2 \mathrm{~m}$ and $0.7 \mathrm{~m}$, respectively.

(4) Section of intake 4

The section is both erosion and deposition in all conditions. There is slight deposit about $0.5-2.0 \mathrm{~m}$ thickness at left bank beach generally. The bed of the main channel and right bank beach is scoured about $1-3 \mathrm{~m}$. And the maximum thickness of bed erosion and deposition is $5.9 \mathrm{~m}$ and $2.6 \mathrm{~m}$, respectively. On the other hand ,the maximum thickness of bed erosion and deposition at intake gate is $1.9 \mathrm{~m}$ and $1.6 \mathrm{~m}$, respectively.

Tab.3 give the vertical average sediment concentration at each intake.Tab. 4 give the recommended bottom elevation of each intake gate.

The vertical average sediment concentration at each intake is closely related to sediment incoming, i.e. the bigger sediment concentration incoming, the bigger sediment concentration at each intake.

Table 3. The vertical average sediment concentration at each intake unit: $\mathrm{kg} / \mathrm{m}^{3}$.

\begin{tabular}{|c|c|c|c|c|c|c|c|c|c|c|}
\hline \multirow[t]{2}{*}{ Case } & \multicolumn{2}{|c|}{$\begin{array}{l}\text { Sediment concentration } \\
\text { incoming }\end{array}$} & \multicolumn{2}{|c|}{ Intake 1} & \multicolumn{2}{|c|}{ Intake 2} & \multicolumn{2}{|c|}{ Intake 3} & \multicolumn{2}{|c|}{ Intake 4} \\
\hline & Max & Min & Max & Min & Max & Min & Max & Min & Max & Min \\
\hline Wet year & 0.975 & 0.028 & 0.926 & 0.032 & 0.935 & 0.032 & 0.951 & 0.032 & 0.959 & 0.032 \\
\hline $\begin{array}{l}\text { Moderate } \\
\text { year }\end{array}$ & 0.309 & 0.063 & 0.309 & 0.073 & 0.308 & 0.071 & 0.31 & 0.071 & 0.312 & 0.068 \\
\hline Dry year & 0.271 & 0.035 & 0.28 & 0.041 & 0.276 & 0.041 & 0.276 & 0.041 & 0.279 & 0.036 \\
\hline Series years & 0.975 & 0.028 & 0.939 & 0.031 & 0.946 & 0.031 & 0.959 & 0.029 & 0.963 & 0.029 \\
\hline
\end{tabular}

According the design data, the water level of $97 \%$ intake guarantee rate is $3.62 \mathrm{~m}$. At the same time, due to the impact of Three Gorges Project and the upstream reservoir, the water level of the intake reach decrease $0.6-0.7 \mathrm{~m}$. Then, overall consideration above factors and computation results, it is suggest that the bottom elevation of mushroom style and box style are less than $-1 \mathrm{~m}$ and $-0.5 \mathrm{~m}$.

Table 4. The recommended bottom elevation of each intake gate.

\begin{tabular}{|c|c|c|c|c|}
\hline Intake position & intake 1 & intake 2 & intake 3 & intake 4 \\
\hline recommended bottom elevation (m) & $-2.5 \sim-1$ & $-4 \sim-1$ & $-2.0 \sim-1$ & -0.5 \\
\hline
\end{tabular}

\section{CONCLUSION}

A 3D numerical model is used to simulate local flows and plane 2D flow and sediment model is used to simulate riverbed erosion-deposition, suspended sediment concentration around submerged water intakes in this paper. And recent future riverbed evolutions around the water intakes were predicted and so on.

(1) Due to the Three Gorges Project operation, the incoming sediment is significantly reduced. So each section riverbed is scouring mainly. 
(2) The results show that the change of riverbed erosion and deposition around the water intake is not only affected by the conditions of incoming water and sediment, but also by the position of the local topography at the same river reach.

(3) The riverbed variation follows the law of sediment deposition on high-water period and sediment erosion on low-water period.

(4) The vertical average sediment concentration at each intake is closely related to sediment incoming, i.e. the bigger sediment concentration incoming, the bigger sediment concentration at each intake.

\section{ACKNOWLEDGMENT}

The financial support by the national natural science foundation of china (51339001) are gratefully acknowledged.

\section{REFERENCES}

[1] CHEN Huiquan, Xu Yulin, HE Yiying. Progress and experience of 50 years' study on cooling water circulation of thermal/nuclear power plants [J]. J. of China Institute of Water Resources and Hydropower Research, 2008, 6(4): $288-295$.

[2] DUAN Zhike, LI huimei, Experimental Research on Sediment Problems in Intake Work in Thermal Power Plant [J]. J. of Water Resources and Hydropower Engineering, 1997.7, 29-32.

[3] ZHANG Wei, Study on Regularity of Riverbed Evolution in Fluctuating Backwater Area of Xiujiang River, Guangxi Province [D] Nanjing: HoHai University,2006.

[4] ZHOU Fayi, CHEN Bihong, 3-D simulation of the flow and sediment transport near a water intake [J]. J. of Hydraulic Engineering, 1997 (12): 30-37.

[5] ZHAO Shun'an, DUAN Jiehui, A hydraulic model study on the head of water supply in a drawing project [J]. J. of Hydro. Dynamics (Series A), 2003,18(6): 698-701.

[6] XIE Cuisong, YU Weiqing, YU Minghui, Calculation and Analysis of Influence on Flood Control by Port and Intake Construction [J]. South to North Water Transfers and Water Science \& Technology, 2005, 3(4): 54-58.

[7] ZHANG Xujin, ZHANG Jinlin, ZHOU Qin, ZHANG Zhan, Influence of Reservoir Sediment Deposition on Water-Intake of Power Plant [J], J. of ChongQing JiaoTong University(Nature Science), Vol.32 No.5, 2013.10, 1035-1039.

[8] HU De-chao, LI Xiao-juan, LIAO Yang-sheng, Three-Dimensional numerical simulation of flows around submerged water intake. J. of Yangtze River Scientific Research Institute, 2013, vol.30, No.10: 11-16.

[9] HU D C, FAN B L, WANG G Q, et al. A Semi-implicit 3-D Numerical Model Using Sigma-coordinate for Nonhydrostatic Pressure Free-surface Flows [J]. J. of Hydrodynamics, 2011, 23(2): 212-223.

[10] HU D C, WANG G Q, ZHANG H W, et al. A Semi-implicit 3-D Numerical Model for Non-hydrostatic Pressure Freesurface Flows on an Unstructured Sigma Grid [J]. International Journal of Sediment Research, 2013, 28(1): 77-89. 